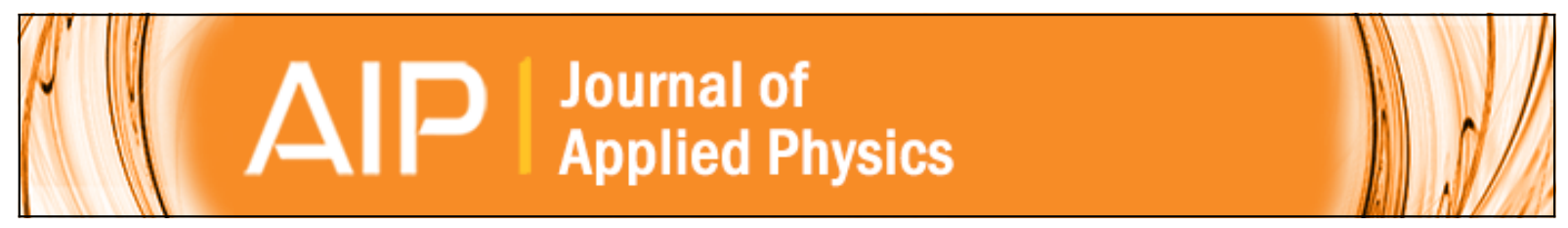

\title{
Suppression of interdiffusion in GaAs/AIGaAs quantum-well structure capped with dielectric films by deposition of gallium oxide
}

L. Fu, J. Wong-Leung, P. N. K. Deenapanray, H. H. Tan, C. Jagadish, Bin Gong, R. N. Lamb, R. M. Cohen, W. Reichert, L. V. Dao, and M. Gal

Citation: Journal of Applied Physics 92, 3579 (2002); doi: 10.1063/1.1503857

View online: http://dx.doi.org/10.1063/1.1503857

View Table of Contents: http://scitation.aip.org/content/aip/journal/jap/92/7?ver=pdfcov

Published by the AIP Publishing

\section{Articles you may be interested in}

Suppression of thermal atomic interdiffusion in C-doped In Ga As/Al Ga As quantum well laser structures using $\mathrm{Ti} O 2$ dielectric layers

Appl. Phys. Lett. 85, 5583 (2004); 10.1063/1.1833563

Impurity-free intermixing of $\mathrm{GaAs} / \mathrm{AlGaAs}$ quantum wells using $\mathrm{SiO}$ x capping: Effect of nitrous oxide flow rate J. Vac. Sci. Technol. B 19, 1962 (2001); 10.1116/1.1406937

Anodic-oxide-induced interdiffusion in GaAs/AIGaAs quantum wells

J. Appl. Phys. 83, 1305 (1998); 10.1063/1.366830

Novel impurity-free interdiffusion in GaAs/AIGaAs quantum wells by anodization and rapid thermal annealing Appl. Phys. Lett. 70, 1269 (1997); 10.1063/1.118549

Suppression of quantum well intermixing in GaAs/AIGaAs laser structures using phosphorus-doped SiO 2 encapsulant layer

J. Appl. Phys. 81, 2445 (1997); 10.1063/1.364295

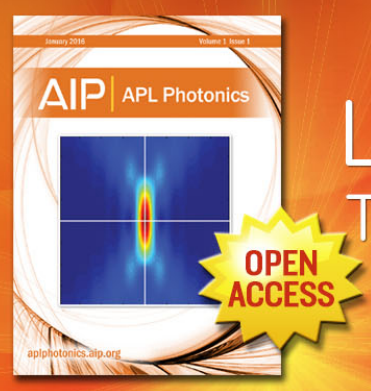

Launching in 2016! The future of applied photonics research is here 


\title{
Suppression of interdiffusion in GaAs/AIGaAs quantum-well structure capped with dielectric films by deposition of gallium oxide
}

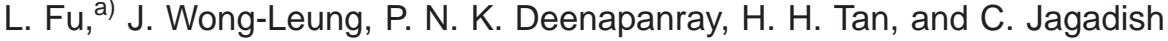 \\ Department of Electronic Materials Engineering, Research School of Physical Sciences and Engineering, \\ The Australian National University, Canberra, ACT 0200, Australia \\ Bin Gong and R. N. Lamb \\ Surface Science and Technology, School of Chemical Sciences, University of New South Wales, Sydney, \\ NSW 2052, Australia \\ R. M. Cohen and W. Reichert \\ Department of Materials Science and Engineering, University of Utah, Salt Lake City, Utah 84112 \\ L. V. Dao and M. Gal \\ School of Physics, University of New South Wales, Sydney 2052, Australia
}

(Received 24 September 2001; accepted for publication 5 July 2002)

\begin{abstract}
In this work, different dielectric caps were deposited on the GaAs/AlGaAs quantum well (QW) structures followed by rapid thermal annealing to generate different degrees of interdiffusion. Deposition of a layer of $\mathrm{Ga}_{x} \mathrm{O}_{y}$ on top of these dielectric caps resulted in significant suppression of interdiffusion. In these samples, it was found that although the deposition of $\mathrm{Ga}_{x} \mathrm{O}_{y}$ and subsequent annealing caused additional injection of $\mathrm{Ga}$ into the $\mathrm{SiO}_{2}$ layer, $\mathrm{Ga}$ atoms were still able to outdiffuse from the GaAs QW structure during annealing, to generate excess Ga vacancies. The suppression of interdiffusion with the presence of $\mathrm{Ga}$ vacancies was explained by the thermal stress effect which suppressed $\mathrm{Ga}$ vacancy diffusion during annealing. It suggests that $\mathrm{Ga}_{x} \mathrm{O}_{y}$ may therefore be used as a mask material in conjunction with other dielectric capping layers in order to control and selectively achieve impurity-free vacancy disordering. (C) 2002 American Institute of Physics. [DOI: 10.1063/1.1503857]
\end{abstract}

\section{INTRODUCTION}

Over the past several years, as a powerful postgrowth technique, quantum well intermixing ${ }^{1}$ (QWI) has been studied extensively. QWI happens through the compositional intermixing (interdiffusion) of the well and barrier atoms in the III-V heterostructure, due to the thermal diffusion of point defects (vacancies or interstitials). Among the various techniques $^{2-5}$ used to create intermixing, impurity free vacancy disordering (IFVD) has been considered to be the most promising technique for device applications due to its simplicity, low optical losses, and low residual damage. ${ }^{6,7}$ However, to realize the monolithic integration of optoelectronic (or photonic) components of different band gap energies across the wafer, which is the main purpose and advantage of QWI, it is essential for the method of intermixing itself to have area selectivity. Unlike ion implantation which is spatially selective, selectivity for IFVD can only be achieved by applying a capping layer which promotes intermixing and another capping layer which prevents intermixing to different regions of the sample. Usually, $\mathrm{SiO}_{2}$ is used to induce IFVD and $\mathrm{Si}_{3} \mathrm{~N}_{4}$ is used to inhibit intermixing. However, some experiments ${ }^{8,9}$ pointed out that under certain deposition conditions, $\mathrm{Si}_{3} \mathrm{~N}_{4}$ also enhanced interdiffusion. Recently, much effort has been made to find a way to suppress and thus control intermixing. For example, some studies ${ }^{10-13}$ found

\footnotetext{
a)Electronic mail: ful109@rsphysse.anu.edu.au
}

that by modifying the properties of the dielectric caps, intermixing could be suppressed. On the other hand, it was proposed ${ }^{14}$ that by depositing a dielectric film onto the GaAs surface of a quantum well (QW) structure, the mismatch in thermal expansion coefficient between these two materials will cause thermal stress at the near-interface regions of dielectric film and QW structure during the annealing process. The type of the thermal stress (whether it is compressive or tensile) generated at the surface of the QW structure will in turn affect the diffusion of Ga vacancies and the extent of intermixing. However, although this thermal stress issue was also considered as a factor affecting IFVD by other researchers, ${ }^{10,15}$ no detailed study has been further reported. To confirm the role of thermal stress in the IFVD process and thus to use it to realize selectivity and controllability of IFVD, in this work, a layer of $\mathrm{Ga}_{x} \mathrm{O}_{y}$ was deposited onto the GaAs/AlGaAs QW structures which were predeposited with different dielectric films, including $\mathrm{SiO}_{2}, \mathrm{Si}_{3} \mathrm{~N}_{4}$, and spin-on glass (SOG). The $\mathrm{Ga}_{x} \mathrm{O}_{y}$ layer was selected since the thermal expansion coefficient of $\mathrm{Ga}_{2} \mathrm{O}_{3}$ is $7.3 \times 10^{-6}{ }^{\circ} \mathrm{C}$ (obtained by averaging the thermal expansion coefficients along $a$ and $c$ axes of $\left.\alpha-\mathrm{Ga}_{2} \mathrm{O}_{3}\right)^{16}$ which is larger than those of the predeposited dielectric films and even GaAs. ${ }^{17}$ It was found that in all cases, with the deposition of $\mathrm{Ga}_{x} \mathrm{O}_{y}$ layers, interdiffusion was significantly suppressed in the QWs after annealing. To reveal the reason for the suppression of interdiffusion, two possibilities are considered: the suppression of Ga outdiffusion from QW structure to the dielectric film (predeposited) 
due to the deposition of $\mathrm{Ga}_{x} \mathrm{O}_{y}$ layer which may provide additional source of $\mathrm{Ga}$ to saturate the dielectric layer; or the suppression of vacancy diffusion due to the change of the thermal stress in the QW structure as a result of the large thermal expansion coefficient of the $\mathrm{Ga}_{x} \mathrm{O}_{y}$ layer. X-ray photoelectron spectroscopy (XPS) and cross-sectional transmission electron microscopy (XTEM) measurements were carried out to clarify this problem.

\section{EXPERIMENTS}

The QW structure used in this experiment was grown on a semi-insulating (100) GaAs substrate by metalorganic chemical vapor deposition (MOCVD). It consisted of four GaAs QWs, $Q W 1, Q W 2, Q W 3, Q W 4$ with different thicknesses, 1.4, 2.3, 4.0, $8.5 \mathrm{~nm}$ (from surface). Each QW was sandwiched between two $50 \mathrm{~nm} \mathrm{Al}_{0.54} \mathrm{Ga}_{0.46}$ As barriers. The structure was then terminated with a $40 \mathrm{~nm}$ GaAs cappinglayer to prevent oxidation of the $\mathrm{Al}_{0.54} \mathrm{Ga}_{0.46} \mathrm{As}$ layer. All layers were undoped and grown at $750{ }^{\circ} \mathrm{C}$. Three pieces of 1 $\mathrm{cm} \times 1 \mathrm{~cm}$ samples were cleaved from the wafer, deposited with three types of dielectric films, $\mathrm{SiO}_{2}, \mathrm{Si}_{3} \mathrm{~N}_{4}$, and spin-on glass, to the thickness of 150-200 nm. Both $\mathrm{SiO}_{2}$ and $\mathrm{Si}_{3} \mathrm{~N}_{4}$ were deposited by plasma enhanced chemical vapor deposition (PECVD) using $\mathrm{N}_{2} \mathrm{O} / \mathrm{SiH}_{4}$ and $\mathrm{NH}_{3} / \mathrm{SiH}_{4}$ flow, respectively, at $35^{\circ} \mathrm{C}$. The SOG film was formed by spinning commercial liquid silica on the sample surface at a speed of 3000 rpm for $30 \mathrm{~s}$ followed by subsequent baking at $400{ }^{\circ} \mathrm{C}$ for 15 min. Half of each dielectric film capped sample were then covered with $\sim 90 \mathrm{~nm} \mathrm{Ga}_{x} \mathrm{O}_{y}$ by MOCVD using $\mathrm{N}_{2} \mathrm{O}$ and trimethylgallium as sources at a temperature of $600^{\circ} \mathrm{C}$ for 20 $\min$. As to the other half of the sample, part of the dielectric film was etched off in $10 \%$ HF to provide an uncapped reference region. All the samples were then rapid thermally annealed (RTA) at $900{ }^{\circ} \mathrm{C}$ for $60 \mathrm{~s}$. During annealing, the etched samples were protected from excessive loss of As by using the proximity capping technique. Low temperature (12 $\mathrm{K})$ photoluminescence (PL) was performed using a green $\mathrm{He}-\mathrm{Ne}$ laser $(543.5 \mathrm{~nm})$ as excitation source and the signal was detected by silicon charge coupled device through a 0.27 m monochromator. XPS (using a VG ESCALAB 220-iXL spectrometer with the monochromated $\mathrm{Al} K \alpha$ X-ray source) and XTEM (using a Philips CM 300 microscope) measurements were performed on selected samples.

\section{RESULTS AND DISCUSSIONS}

Figure 1 shows the PL spectra from four samples, (a) as-grown, (b) as-grown+RTA, (c) as-grown+ $\mathrm{SiO}_{2}(\mathrm{PECVD})+\mathrm{RTA}$ and (d) as-grown $+\mathrm{SiO}_{2}$ (PECVD) $+\mathrm{Ga}_{x} \mathrm{O}_{y}+\mathrm{RTA}$. The four peaks in spectrum (a) originate from the four QWs in the structure. It can be seen that after RTA [spectrum (b)], the four peaks are shifted to lower wavelengths due to thermal intermixing and with the $\mathrm{SiO}_{2}$ capping layer [spectrum (c)], they are shifted further, as normally observed in the IFVD process. Meanwhile, the disappearance of the peak from $Q W 1$ was observed as a consequence of three possibilities, ${ }^{18}$ (i) accumulation of nonradiative defect centres in the near-surface region, (ii) complete intermixing of $Q W 1$, or (iii) change of well com-

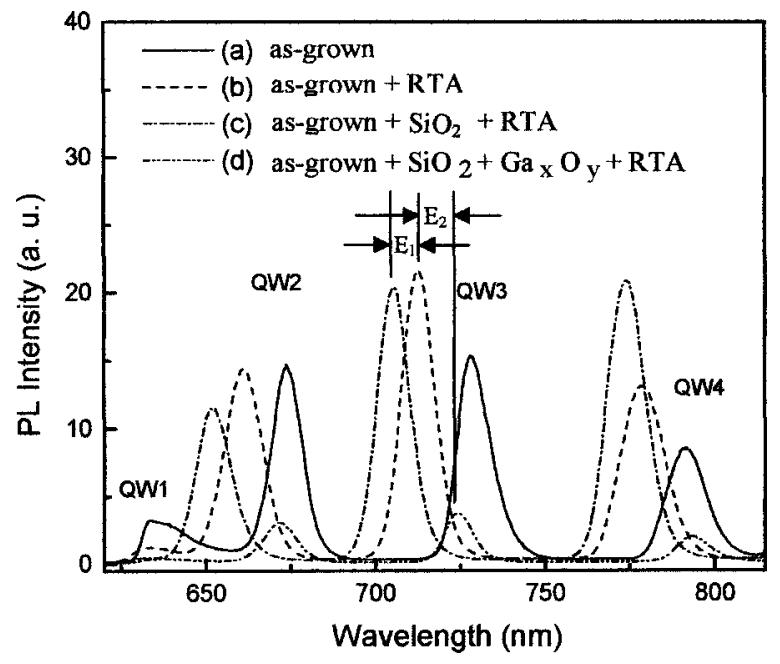

FIG. 1. PL spectra for the $4 \mathrm{QWs}$ GaAs/AlGaAs samples which were (a) as-grown, (b) as-grown and annealed, (c) deposited with $\mathrm{SiO}_{2}$ and annealed, (d) deposited with both $\mathrm{SiO}_{2}$ and $\mathrm{Ga}_{x} \mathrm{O}_{y}$ and annealed. $E_{1}$ and $E_{2}$ are the energy shifts obtained by comparing spectra (c) and (d) between the reference spectrum (b), respectively.

position which makes $Q W 1$ indirect. However, for the sample with $\mathrm{Ga}_{x} \mathrm{O}_{y}$ on top of the $\mathrm{SiO}_{2}$, spectrum (d) exhibits a significant redshift compared with spectra (b) and (c) in all QWs indicating that interdiffusion was suppressed.

The energy shifts $E_{1}$ and $E_{2}$ labeled in Fig. 1 for $Q W 3$ are tabulated in Table I, which are obtained by comparing spectra (c) and (d) with the annealed reference sample spectrum (b), respectively. The positive value of $E_{1}$ means that $\mathrm{SiO}_{2}$ capping enhanced intermixing (in addition to thermal intermixing) by IFVD, whilst the negative value of $E_{2}$ reveals that for the sample capped with both $\mathrm{SiO}_{2}$ and $\mathrm{Ga}_{x} \mathrm{O}_{y}$, not only was IFVD totally suppressed, but also the thermally induced intermixing was partially inhibited. Similar phenomena were observed for the $\mathrm{Si}_{3} \mathrm{~N}_{4}$ and SOG capped samples, as shown in Table I. As expected, for the samples covered only with $\mathrm{SiO}_{2}, \mathrm{Si}_{3} \mathrm{~N}_{4}$, or SOG, different blue shifts of PL energy (positive values of $E_{1}$ ) were obtained in addition to thermal intermixing. Both PECVD and spin-on $\mathrm{SiO}_{2}$ generated more intermixing than $\mathrm{Si}_{3} \mathrm{~N}_{4}$ while the $\mathrm{SOG}$ film generated more intermixing than PECVD $\mathrm{SiO}_{2}$. However, after the deposition of $\mathrm{Ga}_{x} \mathrm{O}_{y}$, interdiffusion promoted by IFVD together with part of thermal interdiffusion was suppressed (negative value of $E_{2}$ ) in all cases.

To investigate whether there is any change in the properties of the dielectric films due to the introduction of $\mathrm{Ga}_{x} \mathrm{O}_{y}$

TABLE I. PL energy shifts for $Q W 3$ obtained by comparing PL spectra in Fig. 1 labeled as $E_{1}$, between spectrum (c) of the $\mathrm{SiO}_{2}$ capped sample and spectrum (b) of the annealed reference sample, and $E_{2}$, between spectrum (d) of the $\mathrm{SiO}_{2}+\mathrm{Ga}_{x} \mathrm{O}_{y}$ capped sample and spectrum (b) of the annealed reference sample. $E_{1}$ and $E_{2}$ for the samples capped with PECVD $\mathrm{Si}_{3} \mathrm{~N}_{4}$ and SOG films are also shown in Table I.

\begin{tabular}{lcc}
\hline \hline & $E_{1}(\mathrm{meV})$ & $E_{2}(\mathrm{meV})$ \\
\hline $\mathrm{PECVD} \mathrm{SiO}_{2}$ & 17.94 & -28.95 \\
$\mathrm{PECVD} \mathrm{Si}_{3} \mathrm{~N}_{4}$ & 14.48 & -20.07 \\
$\mathrm{Spin}_{\mathrm{O}} \mathrm{SiO}_{2}$ & 33.69 & -8.98 \\
\hline \hline
\end{tabular}




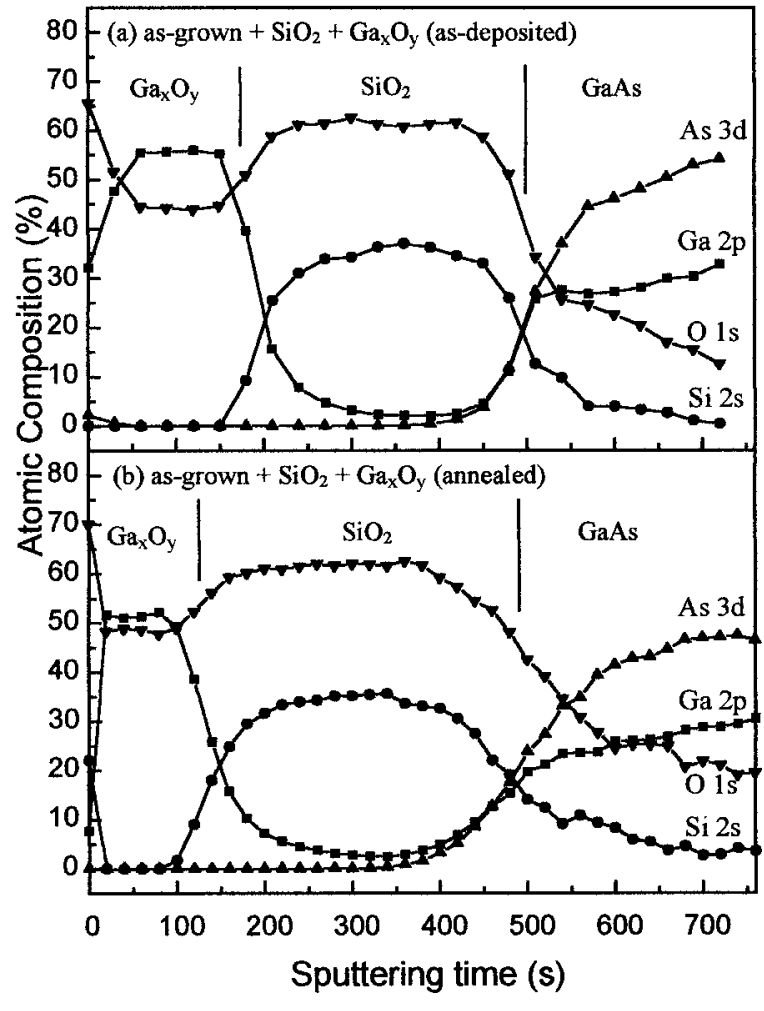

FIG. 2. XPS in-depth profiles of $\mathrm{Ga}, \mathrm{Si}, \mathrm{O}$, and As for the samples which were (a) deposited with both $\mathrm{SiO}_{2}$ and $\mathrm{Ga}_{x} \mathrm{O}_{y}$ (but not annealed) and (b) deposited with both $\mathrm{SiO}_{2}$ and $\mathrm{Ga}_{x} \mathrm{O}_{y}$ and annealed.

during the deposition and annealing processes, the XPS indepth profiling was performed using monochromated $\mathrm{Al} K \alpha$ $\mathrm{x}$-ray source and Ar-ion sputtering at $5 \mathrm{keV}$ beam energy. The profiles of $\mathrm{O}, \mathrm{Si}, \mathrm{Ga}$, and As were measured by recording the $\mathrm{O} 1 s, \mathrm{Si} 2 s, \mathrm{Ga} 2 p_{3 / 2}$, and As $3 d$ photoelectron spectra respectively on two $\mathrm{Ga}_{x} \mathrm{O}_{y}$ deposited samples: (a) asgrown+PECVD $\mathrm{SiO}_{2}+\mathrm{Ga}_{x} \mathrm{O}_{y}$ (as-deposited), (b) as-grown + PECVD $\mathrm{SiO}_{2}+\mathrm{Ga}_{x} \mathrm{O}_{y}$ (annealed), as shown in Fig. 2. It can be seen from Fig. 2(a) that, prior to annealing, there is already some $\mathrm{Ga}(\sim 2 \%-5 \%)$ in the $\mathrm{SiO}_{2}$ layer, which means that during the $600{ }^{\circ} \mathrm{C}, 20$ min deposition process of $\mathrm{Ga}_{x} \mathrm{O}_{y}$, $\mathrm{Ga}$ atoms were injected from the $\mathrm{Ga}_{x} \mathrm{O}_{y}$ and/or QW structure. The $\mathrm{Ga}_{x} \mathrm{O}_{y}$ film deposited on our sample is $\mathrm{Ga}$ rich with the composition of $\mathrm{Ga}_{0.56} \mathrm{O}_{0.44}$. After the RTA at $900^{\circ} \mathrm{C}$ for $60 \mathrm{~s}$, the film became less $\mathrm{Ga}$ rich with the composition of $\mathrm{Ga}_{0.51} \mathrm{O}_{0.49}$ and a change in the shape of the $\mathrm{Ga} 2 p$ profile at the $\mathrm{SiO}_{2} / \mathrm{GaAs}$ interface region can be observed, as shown in Fig. 2(b). To examine whether the injection of Ga during the deposition and annealing processes of $\mathrm{Ga}_{x} \mathrm{O}_{y}$ layer affected the outdiffusion of the Ga atoms from the QW structure, a close comparison of the Ga $2 p$ and $\mathrm{Si} 2 s$ spectra between the two $\mathrm{Ga}_{x} \mathrm{O}_{y}$ capped samples at the $\mathrm{SiO}_{2} / \mathrm{GaAs}$ interface region is displayed in Fig. 3. The spectra from the sample without $\mathrm{Ga}_{x} \mathrm{O}_{y}$ capping (but with $\mathrm{SiO}_{2}$ and RTA) are also plotted in Fig. 3. Since the total thickness of the dielectric layers is different in these samples, the $\mathrm{SiO}_{2} / \mathrm{GaAs}$ interfaces of all the spectra are normalized to correspond to the sputtering time at 1/e peak value of the $\mathrm{Si} 2 s$ spectra. It is noted that the concentration of $\mathrm{Ga}$ in the $\mathrm{SiO}_{2}$ layer capped with $\mathrm{Ga}_{x} \mathrm{O}_{y}$ before RTA (solid squares) is higher than the

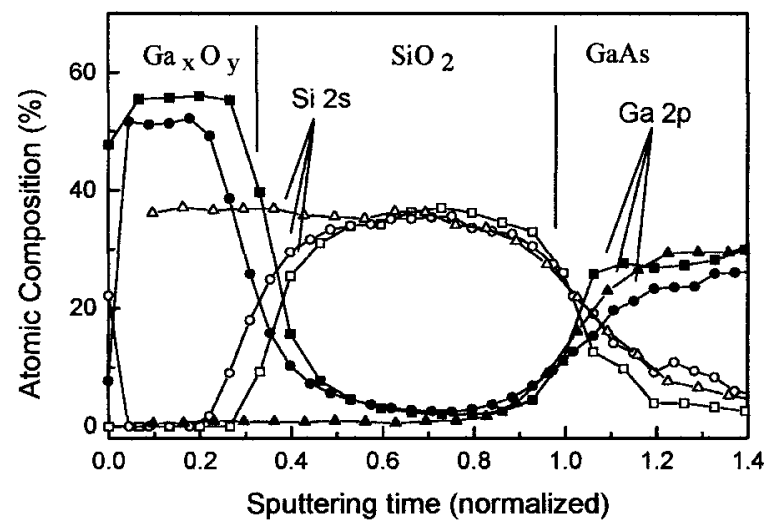

FIG. 3. Normalized XPS in-depth profiles for $\mathrm{Ga}$, $\mathrm{Si}$ at the $\mathrm{SiO}_{2} / \mathrm{GaAs}$ interfaces using the sputtering time at $1 / e$ peak value of the $\mathrm{Si} 2 s$ spectra for the samples which were: as-deposited with both $\mathrm{SiO}_{2}$ and $\mathrm{Ga}_{x} \mathrm{O}_{y}$ (squares), deposited with both $\mathrm{SiO}_{2}$ and $\mathrm{Ga}_{x} \mathrm{O}_{y}$ and annealed (circles), and deposited with only $\mathrm{SiO}_{2}$ and annealed (triangles).

level of $\mathrm{Ga}$ which the uncapped (by $\mathrm{Ga}_{x} \mathrm{O}_{y}$ ) $\mathrm{SiO}_{2}$ (solid triangles) accommodated during our experimental annealing condition. Nevertheless, this does not constitute a restraining force to completely suppress outdiffusion of $\mathrm{Ga}$ into the $\mathrm{SiO}_{2}+\mathrm{Ga}_{x} \mathrm{O}_{y}$ stacking layer from the underneath $\mathrm{GaAs} \mathrm{QW}$ structure. It is clear in Fig. 3 that the annealed $\mathrm{Ga}_{x} \mathrm{O}_{y}$ capped sample (solid circles) has a much diffused transition region in the $\mathrm{Ga}$ profile at the $\mathrm{SiO}_{2} / \mathrm{GaAs}$ interface compared with that of the un-annealed sample (solid squares). Similar Ga profile with diffused transition region at the interface can also be observed in the sample encapsulated only with $\mathrm{SiO}_{2}$ (solid triangles). It indicates that although the deposition of $\mathrm{Ga}_{x} \mathrm{O}_{y}$ and subsequent annealing caused injection of $\mathrm{Ga}$ into the $\mathrm{SiO}_{2}$ layer, it did not fully saturate the $\mathrm{SiO}_{2}$ film, at least in a region adjacent to the $\mathrm{SiO}_{2} / \mathrm{GaAs}$ interface. Gallium atoms were still able to outdiffuse from the GaAs QW structure, leaving behind an excess of vacancies which are expected to promote intermixing in addition to thermal intermixing. However, the PL results presented in Fig. 1 (curve (d) suggest that even with these vacancies in the sample, a blueshift smaller than the thermally induced intermixing is exhibited. To explain this, thermal stress effect ${ }^{14}$ during the IFVD process should be considered.

The mechanism of the IFVD process in GaAs-based system can be divided into two steps which happen almost simultaneously: (i) the generation of gallium vacancies $\left(\mathrm{V}_{\mathrm{Ga}}\right)$, and (ii) the diffusion of $\mathrm{V}_{\mathrm{Ga}}$. The main factors which affect the generation of $\mathrm{V}_{\mathrm{Ga}}$ are the film quality, the diffusion of native defects and the metallurgical reaction between GaAs substrate and the encapsulants. ${ }^{11,19}$ The diffusion of $\mathrm{V}_{\mathrm{Ga}}$ was proposed to be affected by the stress imposed on the semiconductor by the encapsulant(s) in Ref. 14. When GaAs is under compressive stress, the vacancies generated by outdiffusion of $\mathrm{Ga}$ atoms into the encapsulant can be driven to diffuse deeper into the GaAs material to create interdiffusion. However, if the GaAs is under tensile stress, the vacancies will be trapped in the region under stress, making little contribution to interdiffusion. In our experiments, all samples, whether with or without $\mathrm{Ga}_{x} \mathrm{O}_{y}$, were processed from the same wafer and subjected to the same annealing conditions. 
TABLE II. Thermal expansion coefficient, $\alpha$, of the different materials used in this study.

\begin{tabular}{ll}
\hline \hline Material & \multicolumn{1}{c}{$\alpha\left({ }^{\circ} \mathrm{C}^{-1}\right)$} \\
\hline $\mathrm{SiO}_{2}$ & $0.52 \times 10^{-6}$ \\
$\mathrm{Si}_{3} \mathrm{~N}_{4}$ & $2.8 \times 10^{-6}$ \\
$\mathrm{Ga}_{2} \mathrm{O}_{3}$ & $7.3 \times 10^{-6}$ \\
$\mathrm{GaAs}$ & $6.86 \times 10^{-6}$ \\
\hline
\end{tabular}

Therefore, no major variation in the concentration of native defects should be expected from one sample to another. The XPS results showed that although the deposition and annealing of $\mathrm{Ga}_{x} \mathrm{O}_{y}$ caused additional injection of $\mathrm{Ga}$ into the $\mathrm{SiO}_{2}$ film which did change the properties of the $\mathrm{SiO}_{2}$ and may affect the metallurgical reaction at the $\mathrm{SiO}_{2} / \mathrm{GaAs}$ interface, it did not completely suppress the outdiffusion of $\mathrm{Ga}$ from the QW structure. Hence, generation of excess $\mathrm{V}_{\mathrm{Ga}}$ may have been limited, but surely not totally eliminated. The complete suppression of IFVD after $\mathrm{Ga}_{x} \mathrm{O}_{y}$ deposition, especially the partial suppression of thermal intermixing could be correlated only with the change of stress distribution which affects the diffusion of $\mathrm{V}_{\mathrm{Ga}}$.

As shown in Table II, due to the difference in thermal expansion between $\mathrm{GaAs}$ and the dielectric capping film (PECVD $\mathrm{SiO}_{2}, \mathrm{SOG}$, or $\mathrm{Si}_{3} \mathrm{~N}_{4}$ ), during RTA, GaAs surfaces were all under compressive stress which is favourable for creation and diffusion of vacancies. Therefore, the $\mathrm{V}_{\mathrm{Ga}}$ generated below encapsulant/GaAs interface diffused under compressive stress to initiate intermixing. However, the compressive stress generated by $\mathrm{Si}_{3} \mathrm{~N}_{4}$ was obviously smaller than by the other two films, which may lead to a less efficient vacancy diffusion. In addition, $\mathrm{Si}_{3} \mathrm{~N}_{4}$ film is not porous to $\mathrm{Ga}$ or As atoms, ${ }^{14}$ whereas $\mathrm{SiO}_{2}$ is known to be a "sink" for $\mathrm{Ga}$ atoms. Thus, as illustrated by $E_{1}$ in Table I, the smallest energy shift was obtained in the sample covered by $\mathrm{Si}_{3} \mathrm{~N}_{4}$. Between PECVD $\mathrm{SiO}_{2}$ and $\mathrm{SOG}$ which have similar thermal expansion coefficients, the extent of interdiffusion depended only on the quality of capping layers. Our previous results ${ }^{20,21}$ have shown that under the experimental conditions used here, SOG ( $\sim 9 \%$ voids) was more porous than $\mathrm{PECVD} \mathrm{SiO}_{2}(\sim 3 \%$ voids). Consequently, more outdiffusion of $\mathrm{Ga}$ into the dielectric film and more injection of $\mathrm{V}_{\mathrm{Ga}}$ into QW structure were expected for SOG than with PECVD $\mathrm{SiO}_{2}$ film. Accordingly, larger PL energy shift was obtained in the SOG encapsulated structure.

With the deposition of $\mathrm{Ga}_{x} \mathrm{O}_{y}$ on top of these dielectric films, the situation was different. During high temperature annealing, the overall thermal expansion coefficient of the $\mathrm{Ga}_{x} \mathrm{O}_{y}+\mathrm{SiO}_{2}$ bilayer ${ }^{22}$ was greatly increased (due to the large value of the $\mathrm{Ga}_{x} \mathrm{O}_{y}$ 's thermal expansion coefficient), resulting in a much reduced or even eliminated compressive stress in the GaAs surface region below the dielectric film. The $\mathrm{V}_{\mathrm{Ga}}$, including vacancies generated below the encapsulant/GaAs interface by Ga outdiffusion and some of the grown-in vacancies, could not diffuse into the QW region to promote intermixing. Therefore, as suggested by the negative value of $E_{2}$ in Table I, no IFVD was obtained. The relationship between stress field distribution and the thermal
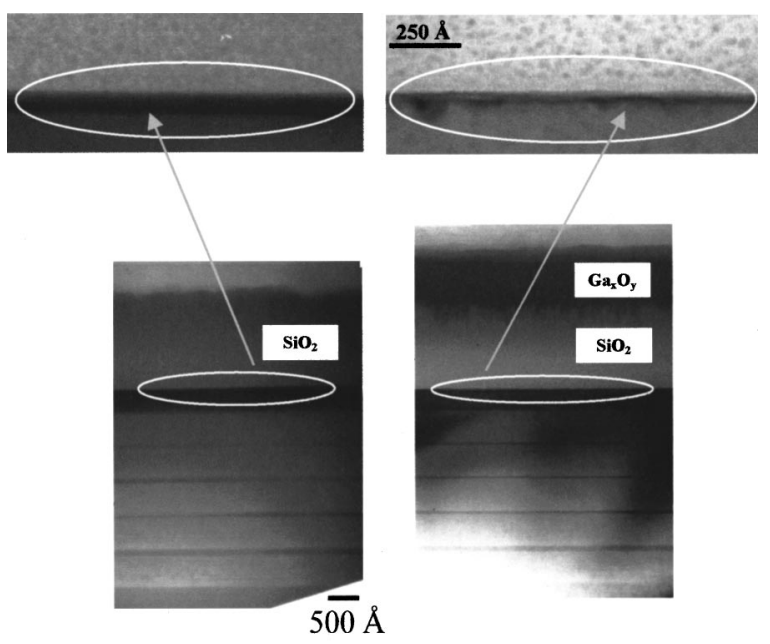

(a)

(b)

FIG. 4. XTEM micrographs of the sample: (a) deposited with $\mathrm{SiO}_{2}$ and annealed at $900{ }^{\circ} \mathrm{C}$ for $60 \mathrm{~s}$, (b) deposited with both $\mathrm{SiO}_{2}$ and $\mathrm{Ga}_{x} \mathrm{O}_{y}$ and annealed at $900{ }^{\circ} \mathrm{C}$ for $60 \mathrm{~s}$. The enlargement of the $\mathrm{GaAs} / \mathrm{SiO}_{2}$ interface area of (a) and (b), defined by the white circle, is also shown, respectively.

expansion coefficient has not been established quantitatively yet. However, it is obvious that the stress field distribution in different samples was varied due to combination of different capping layers and as a result, intermixing was suppressed to a different extent (thus different $E_{2}$ ). In addition, the exact value of $E_{2}$ was also determined by the dielectric film quality (which affects the injection of $\mathrm{Ga}$ from both the $\mathrm{Ga}_{x} \mathrm{O}_{y}$ layer and QW structure) and the grown-in defects in the sample. On the other hand, with the agglomeration of vacancies or other complexes arising from an increase in the As to $\mathrm{Ga}$ ratio in the near-surface region of GaAs due to the lack of compressive stress, the quality of the material might be degraded.$^{14}$ Consequently, a reduction in the PL signal intensity was detected, as shown by spectrum (d) in Fig. 1.

XTEM analysis further confirms the earlier results and the proposed mechanism. Figure 4 displays XTEM micrographs of the samples (a) capped with PECVD $\mathrm{SiO}_{2}$, and (b) capped with the same $\mathrm{SiO}_{2}$ and then $\mathrm{Ga}_{x} \mathrm{O}_{y}$. Both samples were annealed at $900{ }^{\circ} \mathrm{C}$ for $60 \mathrm{~s}$. Clearly, in the sample without the $\mathrm{Ga}_{x} \mathrm{O}_{y}$ layer, some interdiffusion took place as implied by the blurred interfaces between the 4 QWs and their adjacent barriers, whereas with $\mathrm{a}_{x} \mathrm{O}_{y}$ layer the interfaces remained sharp indicating the suppression of intermixing. The GaAs/encapsulant interfaces in Figs. 4(a) and 4(b) are more clearly displayed in the enlargement of the encircled regions. A smooth and uniform dark layer can be observed at the interface in Fig. 4(a), which may be composed of $\mathrm{Ga}_{2} \mathrm{O}_{3}$ and As layers ${ }^{23}$ formed due to the $\mathrm{Ga}$ atoms outdiffusion and/or their metallurgical reaction with $\mathrm{SiO}_{2}$ during RTA. At the interface displayed in Fig. 4(b), a thinner layer can also be seen and as discussed earlier, this may be due to the suppression of $\mathrm{Ga}$ outdiffusion in this sample. Furthermore, a group of defects was observed below the dark layer. These defects were variable in size but had a typical average diameter of $\sim 10 \mathrm{~nm}$. Because of their small size, the nature of the defects could not be determined by electron diffraction. However, they appeared to be very similar to the 
defects observed in the sample capped with a $\mathrm{SiO}_{2}+\mathrm{Si}_{3} \mathrm{~N}_{4}$ bilayer shown in Ref. 14, where intermixing of QWs was also suppressed. It is likely that the formation of these defects was related to the thermal stress and was responsible for the degradation in PL intensity.

It should be noted that this thermal stress effect occurs only during annealing. No matter whether the as-deposited dielectric film is tensile or compressive, the decisive factor affecting interdiffusion is the thermal stress induced in the GaAs surface by the overall influence of the encapsulants. Therefore, for some of the recent reports on suppression of intermixing using $\mathrm{SrF}_{2}, \mathrm{BaF}_{2}, \mathrm{CaF}_{2}, \mathrm{MgF}_{2}$ capping, or $\mathrm{Ge}$, $\mathrm{Al}$ interlayer, ${ }^{24-27}$ it is worth considering carefully the effect of thermal stress in addition to the film quality, metallurgical reactions, and diffusion barrier effects, since all these layers have very different thermal expansion coefficients. Furthermore, new experiments should be designed to systematically study this effect to control intermixing and apply it to the device fabrication.

\section{SUMMARY}

It is demonstrated that during the IFVD process, the diffusion of Ga vacancies depends highly on the stress field distribution in the semiconductor material. With the deposition of $\mathrm{Ga}_{x} \mathrm{O}_{y}$ on top of the different dielectric films which are commonly used to promote interdiffusion, significant suppression of interdiffusion (especially including component of thermal intermixing) was observed. It was ascribed to the modification of stress field by the large thermal expansion coefficient of $\mathrm{Ga}_{x} \mathrm{O}_{y}$, suggesting that this method may be promising in achieving the controlled defect engineering required for any successful application of IFVD.

\section{ACKNOWLEDGMENTS}

The authors would like to thank Dr. N. J. Welham and Dr. John Fitz Gerald for fruitful discussions. J. Wong-Leung, P. N. K. Deenapanray, and H. H. Tan acknowledge the fellowships awarded by the Australian Research Council.

\footnotetext{
${ }^{1}$ Quantum Well Intermixing for Photonics, edited by E. H. Li (SPIE, Bellingham, WA, 1997).

${ }^{2}$ W. D. Laidig, N. Holonyak, Jr., M. D. Camras, K. Hess, J. J. Coleman, P.
}

D. Dapkus, and J. Berdeen, Appl. Phys. Lett. 38, 776 (1981).

${ }^{3}$ P. Gavrilovic, D. G. Deppe, K. Meehan, N. Holonyak, and J. J. Coleman, Superlattices Microstruct. 47, 130 (1985).

${ }^{4}$ D. Kirillov, J. L. Merz, P. D. Dapkus, and J. J. Coleman, J. Appl. Phys. 55, 1105 (1984).

${ }^{5}$ H. H. Tan, J. S. Williams, C. Jagadish, P. T. Burke, and M. Gal, Appl. Phys. Lett. 68, 2401 (1996).

${ }^{6}$ A. C. Bryce, F. Camacho, P. Cusumano, and J. H. Marsh, IEEE J. Sel. Top. Quantum Electron. 3, 885 (1997).

${ }^{7}$ J. H. Marsh, P. Cusumano, A. C. Bryce, B. S. Ooi, and S. G. Ayling, Proc. SPIE 74, 2401 (1995)

${ }^{8}$ W. J. Choi, J. I. Lee, I. K. Han, K. N. Kang, Y. Kim, H. L. Park, and K. Cho, J. Mater. Sci. Lett. 13, 326 (1994).

${ }^{9}$ W. J. Choi, S. Lee, Y. Kim, S. K. Kim, J. I. Lee, K. N. Kang, N. Park, H. L. Park, and K. Cho, J. Mater. Sci. Lett. 14, 1433 (1995).

${ }^{10}$ P. Cusumano, B. S. Ooi, A. Saher Helmy, S. G. Ayling, A. C. Bryce, J. H. Marsh, B. Voegele, and M. J. Rose, J. Appl. Phys. 81, 2445 (1997).

${ }^{11}$ R. M. Cohen, G. Li, C. Jagadish, P. T. Burke, and M. Gal, Appl. Phys. Lett. 73, 803 (1998)

${ }^{12}$ A. Saher Helmy, S. K. Murad, A. C. Bryce, J. S. Aitichison, J. H. Marsh, S. E. Hicks, and C. D. W. Wilkinson, Appl. Phys. Lett. 74, 732 (1999).

${ }^{13}$ L. Fu, R. W. v. d. Heijden, H. H. Tan, C. Jagadish, L. V. Dao, and M. Gal, Appl. Phys. Lett. 80, 1171 (2002).

${ }^{14}$ A. Pépin, C. Vieu, M. Schneider, H. Launois, and Y. Nissim, J. Vac. Sci. Technol. B 15, 142 (1997).

${ }^{15}$ P. N. K. Deenapanray and C. Jagadish, Electrochem. Solid-State Lett. 4, G11 (2001); J. Vac. Sci. Technol. B 19, 1962 (2001).

${ }^{16}$ L. J. Eckert and R. C. Bradt, J. Am. Ceram. Soc. 56, 229 (1973).

${ }^{17}$ From the x-ray photoelectron spectroscopic study, it is found that the $\mathrm{Ga}_{x} \mathrm{O}_{y}$ films deposited in our experiments are $\mathrm{Ga}$ rich. So far we cannot find a report on the thermal expansion coefficients of the $\mathrm{Ga}_{x} \mathrm{O}_{y}$ films which have similar compositions as ours. However it is reasonable to presume that the thermal expansion coefficient of Ga-rich $\mathrm{Ga}_{x} \mathrm{O}_{y}$ films do not differ greatly from that of $\mathrm{Ga}_{2} \mathrm{O}_{3}$.

${ }^{18}$ P. N. K. Deenapanray, H. H. Tan, M. I. Cohen, K. Gaff, M. Petravic, and C. Jagadish, J. Electrochem. Soc. 147, 1950 (2000).

${ }^{19}$ S. Bürkner, M. Maier, E. C. Larkins, W. Rothemund, E. P. O'Reilly, and J. D. Ralston, J. Electron. Mater. 24, 805 (1995).

${ }^{20}$ L. Fu, P. N. K. Deenapanray, H. H. Tan, C. Jagadish, L. V. Dao, and M. Gal, Appl. Phys. Lett. 76, 837 (2000)

${ }^{21}$ P. N. K. Deenapanray, H. H. Tan, L. Fu, and C. Jagadish, Electrochem. Solid-State Lett. 3, 196 (2000).

${ }^{22}$ A. Witvrouw and F. Spaepen, J. Appl. Phys. 73, 7344 (1993).

${ }^{23}$ M. Katayama, Y. Tokuda, N. Ando, Y. Inoue, A. Usami, and T. Wada, Appl. Phys. Lett. 54, 2559 (1989).

${ }^{24}$ I. Gontijo, T. Krauss, R. M. De La Rue, J. S. Roberts, and J. H. Marsh, Electron. Lett. 30, 145 (1994).

${ }^{25}$ I. Gontijo, T. Krauss, J. H. Marsh, and R. M. De La Rue, IEEE J. Quantum Electron. 30, 1189 (1994).

${ }^{26}$ J. H. Teng, S. J. Chua, G. Li, A. S. Helmy, and J. H. Marsh, Appl. Phys. Lett. 76, 1582 (2000).

${ }^{27}$ J. H. Teng, S. J. Chua, Y. H. Huang, G. Li, Z. H. Zhang, A. S. Helmy, and J. H. Marsh, J. Appl. Phys. 88, 3458 (2000). 